Review

\title{
Current Status of the Application of Intracranial Venous Sinus Stenting
}

\author{
Kan $\mathrm{Xu}^{1^{*}}$, Tiecheng $\mathrm{Yu}^{2^{*}}$, Yongjie Yuan ${ }^{1}$, Jinlu $\mathrm{Yu}^{1 \bowtie}$ \\ 1. Department of Neurosurgery, First Hospital of Jilin University, Changchun, 130021, P.R. China \\ 2. Department of Orthopedics, First Hospital of Jilin University, Changchun, 130021, P.R. China \\ ${ }^{*}$ Kan $\mathrm{Xu}$ and Tiecheng Yu contributed equally to the work. \\ $\triangle$ Corresponding author: Jinlu Yu. Department of Neurosurgery, First Hospital of Jilin University, 71 Xinmin Avenue, Changchun 130021, China. \\ Email: jinluyu@hotmail.com
}

(C) 2015 Ivyspring International Publisher. Reproduction is permitted for personal, noncommercial use, provided that the article is in whole, unmodified, and properly cited. See http://ivyspring.com/terms for terms and conditions.

Received: 2015.05.05; Accepted: 2015.09.02; Published: 2015.09.19

\begin{abstract}
The intracranial venous sinus is an important component of vascular disease. Many diseases involve the venous sinus and are accompanied by venous sinus stenosis (VSS), which leads to increased venous pressure and high intracranial pressure. Recent research has focused on stenting as a treatment for VSS related to these diseases. However, a systematic understanding of venous sinus stenting (VS-Stenting) is lacking. Herein, the literature on idiopathic intracranial hypertension (IIH), venous pulsatile tinnitus, sinus thrombosis, high draining venous pressure in dural arteriovenous fistula (AVF) and arteriovenous malformation (AVM), and tumor-caused VSS was reviewed and analyzed to summarize experiences with VS-Stenting as a treatment. The literature review showed that satisfactory therapeutic effects can be achieved through stent angioplasty. Thus, the present study suggests that selective stent release in the venous sinus can effectively treat these diseases and provide new possibilities for treating intracranial vascular disease.
\end{abstract}

Key words: venous sinus, stenting, treatment

\section{Introduction}

The intracranial venous sinus system is important for intracranial vascular disease and is involved in many intracranial vascular diseases, such as idiopathic intracranial hypertension (IIH), venous pulsatile tinnitus, venous sinus thrombosis, high draining venous pressure in dural arteriovenous fistula (AVF) and arteriovenous malformation (AVM), and tumor-caused venous sinus stenosis (VSS) [1-5]. Most of these diseases are associated with VSS, and venous sinus stenting (VS-Stenting) has therefore become a new method for treatment and a current research focus. However, the VS-Stenting application is not well understood. Thus, in this paper, we provide a retrospective analysis of the current literature for treating these diseases through a systematic literature review.

\section{Stent application in idiopathic intra- cranial hypertension}

$\mathrm{IIH}$ is common in obese women of childbearing age and is associated with major symptoms of increased intracranial pressure (ICP), such as headache, papilledema and visual field damage. The causes of IIH remain unclear, and the main treatment consists of medication and optic nerve sheath fenestration to alleviate vision and cerebrospinal fluid shunting to lower ICP [1]. Studies in recent years show that endovascular treatment is a good choice for treating $\mathrm{IIH}$-associated transverse sinus and sigmoid sinus stenosis by releasing a stent in the stenosis area [6, 7]. VS-Stenting therapy has frequently been applied in recent years, with a rapid outpouring of literature; thus, we review the literature herein. Idiopathic Intracranial Hypertension, Pseudotumor Cerebri and Venous Sinus Stenting were searched in PubMed to obtain 
English literature published after 2000 that adopted a multi-case study, review or mono-case report of great significance.

\section{(1)The effectiveness of VS-Stenting therapy for IIH}

Thus far, VS-Stenting therapy for IIH with VSS has been acknowledged by the field. Starke et al. reviewed 185 cases and 211 VS-Stenting therapy instances in 17 studies from 2002 to 2014 and considered the VS-Stenting therapy with VSS for IIH a secure, reliable and effective method. The bilateral pressure gradient of the stenosis was $20.1 \mathrm{mmHg}$ on average (range 19.4-20.7 $\mathrm{mmHg}$ ) preoperatively but decreased to $4.4 \mathrm{mmHg}$ (range $3.5-5.2 \mathrm{mmHg}$ ) postoperatively with fewer complications [8].

Puffer and others reviewed the literature published before 2013 and summarized 143 cases of IIH caused by using VS-Stenting to treat sinus stenosis. The average preoperative sinus pressure gradient across the stenosis was $21.8 \mathrm{mmHg}$ (range 4-160 $\mathrm{mmHg}$ ), and the postoperative pressure gradient across the stent decreased to $2.8 \mathrm{mmHg}$ (range 0-23 $\mathrm{mmHg}$ ); the surgical success rate was $94 \%$, with an overall surgical complication rate of $6 \%$; the headache remission rate was $88 \%$; the papilledema remission rate was $97 \%$; and the field damage mitigation rate was $87 \%$. These data indicate that using stenting to treat VSS-caused IIH can yield good results [9]. Later, Teleb et al. also reviewed 207 cases published in the literature before 2013 and provided conclusions similar to those reported by Puffer [10].

Certain data were distinctive due to the variable number of cases included in the above reviews and because certain cases included a large annual gap. However, the data confirmed that VS-Stenting was an effective therapy for IIH induced by VSS.

\section{(2) Indication of VS-Stenting therapy for IIH}

Currently, the literature does not include a unified standard for indications of IIH caused by VSS, but scholars believe that the pressure gradient is the most important factor. A review by Teleb proposed key and secondary standards for VS-Stenting, in which the key standards were as follows: significant intracranial hypertension, failed conservative treatment and a pressure gradient across the stenosis greater than $8 \mathrm{mmHg}$ with a VSS $>50 \%$ as the secondary standard [10]. However, many studies reported in the literature used $10 \mathrm{mmHg}$ as the therapeutic standard, such as a study by Bussière and others in 2010, in which $10 \mathrm{mmHg}$ was used as the standard in treatment. However, in this paper, VSS was divided into four levels, <25\%, 25\% $-50 \%, 50 \%$ $75 \%$ and $>75 \%$; these levels were not used as the standard in treatment because there were cases with severe stenosis but a normal pressure gradient [11]. Since that study, many other studies have adopted 10 $\mathrm{mmHg}$ as the therapeutic standard, such as in an investigation of 15 cases by Fields and others (2013), in which $10 \mathrm{mmHg}$ was used as the therapeutic standard, while the importance of signs and symptoms was stressed, including headache and papilledema [12]. Ducruet et al. studied 30 cases of IIH VS-Stenting in 2014 using a stenosis level greater than $50 \%$ and a pressure gradient greater than $10 \mathrm{mmHg}$ as the standards, which produced good treatment outcomes [13].

\section{(3) Current studies on VS-Stenting therapy for IIH}

VS-Stenting therapy was first applied for IIH induced by VSS circa 2000. For example, Higgins et al. reported an attempt at using VS-Stenting for 12 cases of IIH in 2003; 5 cases were unimproved. In a retrospective study of these 5 cases, scholars considered improper selection of the cases (VSS may not have mostly contributed to the IIH) or inadequate relief of venous sinus inner pressure after VS-Stenting the basis for the outcome [14]. The attempt by Higgins et al. laid a foundation for VS-Stenting therapy of IIH. Nine cases conducted by Owler et al. in 2003 highlighted direct retrograde cerebral venography and manometry for characterizing the morphological features and venous pressures in cerebral venous sinuses and provided radiographic and hemodynamic support for VS-Stenting therapy. Eight out of nine cases yielded satisfactory results, but the remaining case did not show improved symptoms despite the recovery of venous sinus pressure, indicating other causes for IIH [15]. In treating patients for IIH induced by VSS, prognoses greatly improved when hemodynamics and indication selection were emphasized more. For instance, in 18 cases reported by Kampe, indications were emphasized more (the exact pressure gradient induced by clear venous sinus obstruction, which, in turn, caused increased intracranial pressure and optic papilla edema, etc.). These data show that the VS-Stenting treatment is more effective in such cases, with good outcomes in these 18 cases [16].

Currently, VS-Stenting is mainly applied in chronic progressive IIH. The time for diagnosis and treatment is better with chronic IIH; thus, a thorough examination and evaluation can be conducted. Fewer studies have reported on acute IIH sinus stenting. For example, Teleb et al. reported a case of fulminant IIH in 2012 in which the symptoms were exacerbated after performing a diagnostic lumbar puncture; thus, sinus stenting was conducted immediately, and the outcome was good [17]. Elder et al. (2015) reported four 
cases of fulminant IIH in which temporary treatment via cerebrospinal fluid shunting or lumbar drainage was conducted followed by transverse sinus stenting, and good results were obtained in 3 patients [18]. These results indicate that with perioperative symptomatic treatment, VS-Stenting shows good prospects for treating anomalous fulminant IIH.

In conventional IIH-related venous sinus stent release, only the pressure gradient across the stenosis is measured, and the surgery is considered effective if the sinus pressure gradient decreases upon stent release. However, recent studies suggest that simultaneous ICP detection represents a more direct observation of ICP decrease. For example, Fargen et al. (2013) reported a case of stent implantation in a young woman in which the ICP decreased from $70 \mathrm{cmH}_{2} \mathrm{O}$ to $20 \mathrm{cmH}_{2} \mathrm{O}$ and remained at normal levels for 24 hours [19]. ICP monitoring was also used in a video presentation by Ding et al. (2014) [20]. In addition to ICP monitoring, Esfahani et al. (2015) proposed and used quantitative magnetic resonance venography (qMRV) to detect changes in blood flow before and after stent release in 5 cases and suggested that qMRV exhibited the potential for application in sinus stenting [21].

The major mechanism associated with using stenting to treat VSS-caused IIH is that stent release can significantly decrease the across-stenosis pressure gradient and sinus pressure and promote cerebrospinal fluid adsorption to decrease ICP, which improves clinical symptoms [1]. Even in patients with bilateral VSS, unilateral stenting is effective [22]. In addition to reducing venous sinus pressure, hemodynamic factors are involved in the mechanism underlying the effect of stenting on IIH. Lazzaro et al. (2012) reported good outcomes from using stenting to treat 3 patients with stenoses $>70 \%$ and an across-stenosis pressure gradient greater than 30 $\mathrm{mmHg}$; their investigation of hemodynamics before and after stent placement showed that attenuated blood flow pulsation, pressure gradient correction and improved blood flow are the bases for stenting's efficacy in treating IIH [23]. Nevertheless, stent release failed to alleviate clinical symptoms in certain patients. For example, Goodwin et al. (2014) reported 18 cases of using a sinus stent to treat IIH, among which three cases exhibited poor results, and cerebrospinal fluid shunting was performed; thus, the researchers speculated that the cause of IIH may be more complicated [24].

\section{(4) An argument for using VS-Stenting therapy in IIH}

Intracranial VSS may cause increased intracranial pressure. Considerably severe VSS triggers intracranial venous return obstruction, which induces increased intracranial pressure [25]; venous return obstruction can also affect cerebrospinal fluid absorption, which causes the intracranial pressure to increase and exacerbate venous sinus stenosis, forming a vicious circle (Figure 1). VS-Stenting therapy was effective for these types of patients. In contrast, the venous sinus may be pressed to constrict due to increased intracranial pressure, causing a mistake wherein venous stenosis produces increased intracranial pressure. Such patients were common in obese women under 45 years old. The morbidity should meet the diagnostic criteria of Modified Dandy Criteria as follows. Signs and symptoms of increased intracranial pressure. $b$. No localizing focal neurological signs except unilateral or bilateral sixth nerve paresis. c. CSF opening pressure greater than $25 \mathrm{~cm}$ of water but without cytological or chemical abnormalities. d. Normal neuroimaging adequate to exclude cerebral venous thrombosis, that is, MRI of the brain often with additional sequences. Therefore, the patients' condition during morbidity and auxiliary examination was of great significance [26]. VS-Stenting therapy for such IIH patients was not satisfactory.

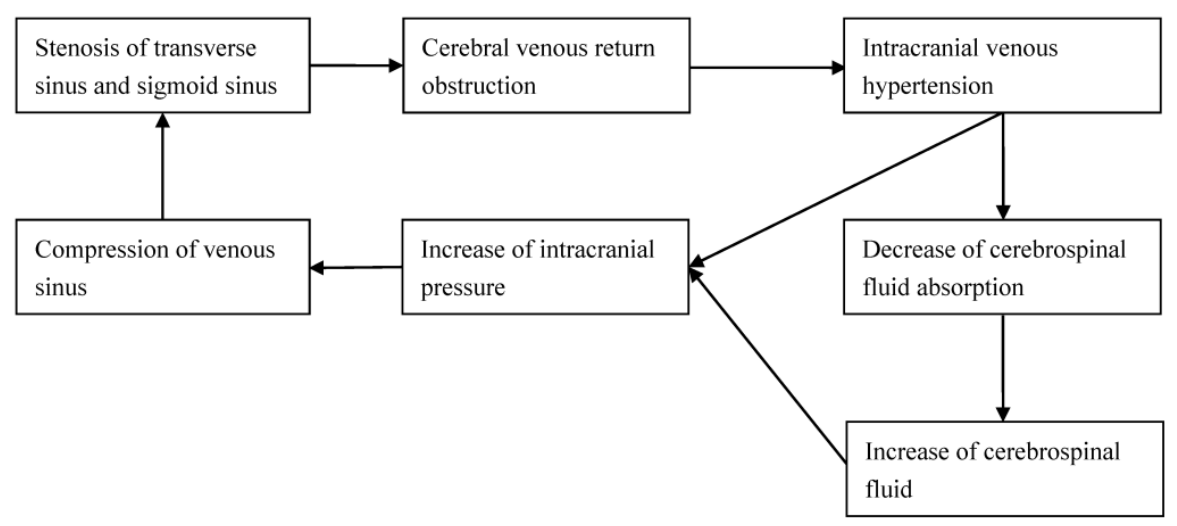

Figure 1. Mechanism for increased intracranial pressure induced by venous sinus stenosis 
Thus, Kumpe stressed the indication of IIH combined with VSS. For example, patients with a clear pressure gradient induced by a clear venous sinus obstruction, which, in turn, increased intracranial pressure and optic papilla edema, would obtain better results when VS-Stenting therapy was applied [16].

Using stenting to treat VSS-accompanied IIH remains controversial because not all increases in ICP are caused by transverse sinus stenosis. Therefore, $\mathrm{IIH}$ accompanied by VSS is still referred to as IIH instead of being classified as secondary IIH caused by VSS [27]. In contrast, certain cases of bilateral transverse sinus stenosis show no increase in ICP, such as in the 7 cases reported by Kelly et al. (2012) [28]. Therefore, the relationship between VSS and increased ICP is not fully understood. Furthermore, whether the implanted stent affects the draining veins that drain into the venous sinus remains controversial. However, after studying 41 instances of lateral VS-Stenting in 38 patients, Levitt et al. (2015) concluded that the stent would not affect draining veins such as the Labbé vein [29]. In addition, low rates of complications in applying stenting for treating $\mathrm{IIH}$, such as infection and restenosis, have been reported in the literature, and the costs are lower than shunting surgery [30]. Thus, with increasing clinical practice and consistently improving clinical indications, stenting will show broader application prospects in $\mathrm{IIH}$ treatment. A summary of the literature reviewed is shown in Table 1.

\section{(5) Conclusion on VS-Stenting therapy for IIH}

$\mathrm{IIH}$ induced by VSS should be distinguished from IIH combined with VSS when confronted with $\mathrm{IIH}$ and VSS simultaneously. VS-Stenting provided good outcomes for IIH induced by VSS. A meta-analysis was required to supply evidence and judge the effects of VS-Stenting.

\section{Stent application in venous pulsatile tinnitus}

Pulsatile tinnitus can have many causes. For example, some cases are caused by sinus disease, such as VSS and sinus aneurysms or diverticulum. This type of tinnitus coincides with the beating of the heart and decreases with increasing venous pressure, such as through oppression of the jugular vein or turning of the head [31]. This type of tinnitus can be treated with VS-Stenting or stent-assisted coiling.

Pulsatile tinnitus and Venous Sinus Stenting were used to search PubMed for published English literature that adopted a multi-case study, review or mono-case report of great significance. Based on a literature review, we believe that the causes of sinus disease-caused pulsatile tinnitus can be divided into three categories: (1) Type I: VSS with no increase in ICP, (2) Type II: IIH-accompanied VSS and (3) Type III: venous sinus aneurysm or diverticulum. These 3 categories are reviewed below.

Table 1. Reviewed literature on IIH stenting

\begin{tabular}{|c|c|c|c|}
\hline Year & Author & Title & Research content \\
\hline 2013 & Puffer [9] & $\begin{array}{l}\text { Venous sinus stenting for idiopathic intracranial hypertension: a } \\
\text { review of the literature }\end{array}$ & $\begin{array}{l}\text { Reviewed } 143 \text { cases from before } 2013 \text { and summarized the treatment } \\
\text { effect, which suggested that stenting was effective in } 80 \% \text { of the patients. }\end{array}$ \\
\hline 2013 & Teleb [10] & $\begin{array}{l}\text { Idiopathic Intracranial Hypertension. A Systematic Analysis of } \\
\text { Transverse Sinus Stenting }\end{array}$ & $\begin{array}{l}\text { Reviewed } 202 \text { cases from before } 2013 \text { and summarized the treatment } \\
\text { effect, which was similar to that reported by Puffer. The standard pri- } \\
\text { mary and secondary stenting treatments for IIH were included. }\end{array}$ \\
\hline 2012 & Lazzaro [23] & $\begin{array}{l}\text { Venous sinus pulsatility and the potential role of dural incom- } \\
\text { petence in idiopathic intracranial hypertension }\end{array}$ & $\begin{array}{l}\text { Pulsatility attenuation, correction of the blood pressure gradient and } \\
\text { amelioration of blood flow were indicated as the bases for the IIH } \\
\text { stenting treatment. }\end{array}$ \\
\hline 2010 & $\begin{array}{l}\text { Bussière } \\
{[11]}\end{array}$ & $\begin{array}{l}\text { Unilateral transverse sinus stenting of patients with idiopathic } \\
\text { intracranial hypertension }\end{array}$ & $\begin{array}{l}\text { VSS with a bilateral pressure gradient greater than } 10 \mathrm{mmHg} \text { was con- } \\
\text { sidered the treatment standard. }\end{array}$ \\
\hline 2014 & Ducruet [13] & $\begin{array}{l}\text { Long-term patency of venous sinus stents for idiopathic intra- } \\
\text { cranial hypertension }\end{array}$ & $\begin{array}{l}\text { Stenosis with a degree and pressure gradient greater than } 50 \% \text { and } 10 \\
\mathrm{mmHg} \text {, respectively, was regarded as the treatment standard. }\end{array}$ \\
\hline 2015 & Elder [18] & $\begin{array}{l}\text { Venous sinus stenting is a valuable treatment for fulminant } \\
\text { idiopathic intracranial hypertension }\end{array}$ & $\begin{array}{l}\text { A good treatment effect for explosive IIH with auxiliary cerebrospinal } \\
\text { fluid drainage and diversion was produced using venous sinus stenting. }\end{array}$ \\
\hline 2012 & Teleb [17] & $\begin{array}{l}\text { Pseudotumor cerebri presenting with ataxia and hyper-reflexia in } \\
\text { a non-obese woman treated with sinus stenting }\end{array}$ & $\begin{array}{l}\text { A good treatment effect for explosive IIH was produced using venous } \\
\text { sinus stenting. }\end{array}$ \\
\hline 2013 & Fargen [19] & $\begin{array}{l}\text { Concomitant intracranial pressure monitoring during venous } \\
\text { sinus stenting for intracranial hypertension secondary to venous } \\
\text { sinus stenosis }\end{array}$ & $\begin{array}{l}\text { Stent release and simultaneous detection of intracranial pressure were } \\
\text { performed and recommended for use. }\end{array}$ \\
\hline 2014 & $\begin{array}{l}\text { Goodwin } \\
{[24]}\end{array}$ & $\begin{array}{l}\text { Risk factors for failed transverse sinus stenting in pseudotumor } \\
\text { cerebri patients }\end{array}$ & Invalid cases of stenting and related treatment methods were discussed. \\
\hline 2015 & Levitt [29] & $\begin{array}{l}\text { Venous sinus stenting for idiopathic intracranial hypertension is } \\
\text { not associated with cortical venous occlusion }\end{array}$ & $\begin{array}{l}\text { No effect of the stent on drainage veins, such as the Labbé vein, was } \\
\text { detected. }\end{array}$ \\
\hline
\end{tabular}




\section{(1) VSS-caused pulsatile tinnitus with no in- crease in ICP}

Patients with this type of tinnitus only felt tinnitus with their heart beat and without other symptoms. Neither positive physical signs nor a manifestation of increased intracranial pressure were observed in a physical examination of the nervous system. Routine cranial CT or MRI hardly showed an abnormality. Furthermore, an MRV or a DSA examination did not reveal an abnormality but did show VSS near the cochlear. Researchers speculate that this type of stenosis is not sufficiently severe to induce increased intracranial pressure. Therefore, it was classified as an independent type of tinnitus.

This type of tinnitus shows no accompanying symptoms; therefore, it is difficult to identify this type as being caused by VSS. This type of tinnitus was first described in 1995 by Russell et al. These authors reported 4 cases that showed no increase in ICP, and they believed that the tinnitus was caused by hemodynamics because a sinus angiography showed that the contrast agent was sprayed through the stenosis and formed a vortex in the distal expansion of the sinus, which produced pulsatile tinnitus. This type of tinnitus is often caused by transverse sinus stenosis possibly because the transverse sinus is proximal to the cochlea; when VSS occur, increasing blood flow may also produce sudden pulsatile tinnitus or exacerbate the tinnitus [31]. The above documented cases were not treated, and only the pulsatile tinnitus mechanism was discussed. Following this report, an extended period of time passed before the 46 cases of pulsatile tinnitus treated by stenting were reported by Baomin et al. (2014), in which, with the exception of 3 patients who showed an accompanying increase in ICP, the pulsatile tinnitus was not caused by an increase in ICP or VSS and was therefore compliant with this type of study. These patients were treated with stents, and their tinnitus disappeared after stenting, which indicates high efficacy [2]. These results show that stenting is an effective treatment for this type of tinnitus.

\section{(2) Pulsatile tinnitus caused by $\mathrm{IIH}$-accom- panied VSS}

This type of tinnitus is common in $\mathrm{IIH}$ and has been observed in approximately $40-50 \%$ of IIH cases reported in the literature. The two possible mechanisms for this type of tinnitus are the following: one includes an increase in ICP that affects venous return in the ear, and the other is sinus stenosis-produced local hemodynamic instability $[9,10]$. Good treatment outcomes have been reported for this type of pulsatile tinnitus. In 2008, Donnet et al. reported 9 in 10 cases of IIH that were accompanied by tinnitus, but the tinni- tus disappeared after VS-Stenting therapy, which supports the hypothesis that lowering the intracranial pressure and improving the local hemodynamics of stenosis can ameliorate tinnitus [32].

Among the cases prior to 2013 that were reviewed by Teleb et al., 65 cases of IIH were accompanied by tinnitus, and after a stenting treatment, the tinnitus disappeared in 29 cases, was alleviated in 33 cases and remained the same in 3 cases, yielding an overall effective rate of 95\% [10]. Additionally, among the cases prior to 2013 that were reviewed earlier by Puffer et al., 41 cases included IIH and tinnitus, 38 of which exhibited a disappearance of or an improvement in symptoms after stenting treatment, corresponding to an overall effective rate of 93\% [9]. However, certain studies indicate that the effective rate of treatment for this type of tinnitus does not reach $90 \%$. For example, in a study by Fields et al. (2013), the treatment was effective for 12 out of 15 cases; thus, the effective rate was $80 \%$ [12]. These results suggest that VS-Stenting can be used to effectively treat pulsatile tinnitus caused by IIH-associated VSS.

\section{(3) Pulsatile tinnitus caused by venous sinus diverticulum or dehiscence and aneurysm}

Venous sinus aneurysm and diverticulum or dehiscence can cause tinnitus when it occurs proximal to mastoid air cells. For example, in a study by Schoeff et al. (2014), pulsatile tinnitus occurred in $23 \%$ of patients, was more common in young females and was associated with venous sinus diverticulum or dehiscence [33]. Fewer cases of venous sinus aneurysms have been documented. A review by Lenck et al. (2012) only reported 7 cases of aneurysms, including self-reported cases. Morphology-wise, venous sinus aneurysms are more similar to artery aneurysms but differ from diverticulum or dehiscence. Thus, they are discussed separately in certain studies. The treatment for a venous aneurysm is the same as that for arterial aneurysms, and coiling or stent-assisted coil embolization can be used [34]. Certain diverticulum or dehiscence cases can be treated using endovascular therapies. For example, Grewal et al. (2014) reviewed 10 cases treated with endovascular therapies, some of which were treated through stent release or stent-assisted coil embolization, and the authors stressed that venous sinus diverticulum or dehiscence is the most common identifiable reason for pulsatile tinnitus [35]. Coil embolization can be difficult in certain instances of venous sinus diverticulum or dehiscence due to a large size or complicated morphology; thus, stent release is the only way to improve hemodynamics or treat pulsatile tinnitus symptoms [36]. A summary of the literature reviewed is shown in Table 2. 
Table 2. Reviewed literature on stenting treatment of venous pulsatile tinnitus

\begin{tabular}{|c|c|c|c|c|}
\hline Class & Year & Author & Title & Research content \\
\hline \multirow[t]{2}{*}{ Type I } & 1995 & Russell [31] & $\begin{array}{l}\text { Objective Pulse-Synchronous "Essential" Tinnitus due } \\
\text { to Narrowing of the Transverse Dural Venous Sinus }\end{array}$ & $\begin{array}{l}\text { The first detailed account of pulsatile tinnitus caused by VSS without } \\
\text { intracranial hypertension was described. }\end{array}$ \\
\hline & 2014 & Baomin [2] & $\begin{array}{l}\text { Angioplasty and stenting for intractable pulsatile } \\
\text { tinnitus caused by dural venous sinus stenosis }\end{array}$ & $\begin{array}{l}\text { A good effect was reported from a stenting treatment in } 46 \text { cases, } 43 \text { of } \\
\text { which were without intracranial hypertension and had pulsatile tinnitus as } \\
\text { the only manifestation. }\end{array}$ \\
\hline \multirow[t]{4}{*}{ Type II } & 2008 & Donnet [32] & $\begin{array}{l}\text { Endovascular treatment of idiopathic intracranial } \\
\text { hypertension: clinical and radiologic outcome of } 10 \\
\text { consecutive patients }\end{array}$ & $\begin{array}{l}\text { Ten cases of IIH were reported; } 9 \text { were combined with tinnitus, but all } \\
\text { disappeared after VS-Stenting therapy, supporting the hypothesis that } \\
\text { lowering the intracranial pressure and improving the local hemodynamics } \\
\text { of stenosis can ameliorate tinnitus. }\end{array}$ \\
\hline & 2013 & Teleb [10] & $\begin{array}{l}\text { Idiopathic Intracranial Hypertension. A Systematic } \\
\text { Analysis of Transverse Sinus Stenting }\end{array}$ & $\begin{array}{l}\text { Sixty-five cases of IIH combined with pulsatile tinnitus were reviewed in } \\
2013 \text {, the treatment of which exhibited an efficacy rate higher than } 90 \% \text {. }\end{array}$ \\
\hline & 2013 & Puffer [9] & $\begin{array}{l}\text { Venous sinus stenting for idiopathic intracranial } \\
\text { hypertension: a review of the literature }\end{array}$ & $\begin{array}{l}\text { Forty-one cases of IIH combined with pulsatile tinnitus were reviewed in } \\
2013 \text {, the treatment of which exhibited an efficacy rate higher than } 90 \% \text {. }\end{array}$ \\
\hline & 2015 & Fields [12] & $\begin{array}{l}\text { Dural venous sinus angioplasty and stenting for the } \\
\text { treatment of idiopathic intracranial hypertension }\end{array}$ & $\begin{array}{l}\text { Effective treatment for tinnitus was reported in } 12 \text { of the } 15 \text { patients in the } \\
\text { study for an efficacy rate of } 80 \% \text {. }\end{array}$ \\
\hline \multirow[t]{3}{*}{ Type III } & 2014 & Schoeff [33] & $\begin{array}{l}\text { Imaging prevalence of sigmoid sinus dehiscence } \\
\text { among patients with and without pulsatile tinnitus }\end{array}$ & $\begin{array}{l}\text { The incidence rate of pulsatile tinnitus in venous sinus diverticulum or } \\
\text { dehiscence was reported to be } 23 \% \text { and was higher in young women. }\end{array}$ \\
\hline & 2012 & Lenck [34] & $\begin{array}{l}\text { Pulsatile tinnitus caused by an aneurysm of the } \\
\text { transverse-sigmoid sinus: a new case report and } \\
\text { review of literature }\end{array}$ & $\begin{array}{l}\text { Seven cases of venous sinus aneurysms were reviewed, which revealed } \\
\text { that the effect of interventional therapy is better in these cases. }\end{array}$ \\
\hline & 2014 & Grewal [35] & $\begin{array}{l}\text { Clinical presentation and imaging findings in patients } \\
\text { with pulsatile tinnitus and sigmoid sinus diverticu- } \\
\text { lum/dehiscence }\end{array}$ & $\begin{array}{l}\text { Ten cases of venous sinus diverticulum or dehiscence were reported, } \\
\text { including stenting and stent-assisted coil embolization cases, in which the } \\
\text { effect of interventional therapy was better. }\end{array}$ \\
\hline
\end{tabular}

\section{(4)Conclusion}

Pulsatile tinnitus induced by VSS can be divided into 3 types based on the etiology and combined with IIH. VS-Stenting therapy may be an effective trial.

\section{Stenting in venous sinus thrombosis formation}

Most venous sinus thrombosis can be treated with intravenous anticoagulation therapy. However, even for adequate anticoagulation, symptoms in certain patients may become gradually worse and often require intervention therapy through endovascular mechanical thrombectomy, which depends on various mechanical thrombectomy devices [37]. In certain cases, to restore blood flow in the venous sinus during the mechanical thrombectomy procedure, a balloon venoplasty must be performed, wherein the venous sinus thrombosis is located to facilitate subsequent treatment [38]. If a thrombosis re-forms after a balloon venoplasty and makes the channel built through balloon venoplasty difficult to maintain, stenting can be performed simultaneously. For example, Formaglio et al. (2010) reported that a patient with sigmoid sinus thrombosis was treated with anti-coagulation therapy, balloon angioplasty and venous stent implantation and recovered well [39]. This procedure is similar to intra-arterial thrombectomy, in which stent implantation must be performed if the patient exhibits stenosis after a thrombectomy and balloon expansion is ineffective. Borhani et al. (2014) reviewed 64 cases of mechanical thrombectomy, among which a venous sinus balloon venoplasty was conducted in 12 cases $(18.7 \%)$, and stent placement was conducted after the balloon venoplasty in 3 cases $(4.7 \%)$; the data showed that stent placement may be necessary for patients with venous sinus thrombosis [3].

\section{Draining vein stenting applied in dural AVF and AVM}

Intracranial arteriovenous malformation, intracranial dural arteriovenous malformation and venous Sinus Stenting were searched using PubMed for the published English literature to analyze and summarize the available data.

\section{(1) Stenting therapy for AVF-drained venous sinus}

Dural AVF is now considered more of an acquired disease and is often accompanied by dural venous sinus stenosis or occlusion, resulting in increased pressure of return veins in brain tissues and arterialization of venous blood flow or even reversed blood flow, which leads to intracranial hemorrhage. Currently, AVF treatment mainly includes arterial embolization and venous embolization. These are the main methods for treating AVF [40]. The main purpose is to prevent high-pressure arterial blood within the AVF from undergoing reverse flushing into the cortical draining veins. In AVF treatment, whether transvenous embolization or transarterial embolization is employed, the aim of both methods is to destroy the block; for AVF with VSS, if transvenous embolization or transarterial embolization is difficult, stenting in the VSS can be performed to decrease the pressure in draining veins, reduce bleeding and promote spontaneous healing of the AVF or to create the opportunity for future treatment [41]. Liebig et al. 
(2005) reported four AVF cases that underwent VS-Stenting to reduce venous pressure and the risk of bleeding; 3 were supplemented with arterial or venous embolization AVF, only 1 underwent stent implantation with a small quantity of residual asymptomatic AVF, and all four cases showed good outcomes in the follow-up [41]. Levrier et al. (2006) studied more cases and reported 10 AVF cases, among which 8 cases exhibited draining vein stenosis, 2 cases exhibited thromboses, 6 cases received only a sinus balloon angioplasty and stent angioplasty, and 4 cases underwent stent placement followed by coil-assisted embolization in the AVF orifice; good results were achieved in all cases [4].

Other than treating VSS or AVF with venous sinus thrombosis, stent placement can be used to treat hypoplastic draining veins in AVF to reconstruct the venous sinus [42]. In addition, if acute venous sinus thrombosis formation occurs during transvenous embolization in AVF treatment, stenting can also be conducted. Hirata et al. (2009) reported one such case with a good prognosis [43]. AVF-associated VSS or thrombosis most often affects the transverse sinus and sigmoid sinus; however, VS-Stenting in other areas has also been reported. For example, Ohara et al. (2012) reported an AVF case that involved the superior sagittal sinus and showed intraventricular hemorrhage and sagittal sinus stenosis in digital subtraction angiography (DSA) as well as clogged venous draining. Venous sinus balloon angioplasty and stent placement were conducted followed by transarterial and transvenous embolization to treat AVF, and the patient showed a good prognosis [44]. Takada et al. (2015) reported a case of torcula AVF with thalamic hemorrhage and poor drainage caused by a straight sinus and transverse sinus stenosis in DSA; the stent was placed inside the straight sinus and transverse sinus after a balloon angioplasty, and the patient recovered well in the follow-up. These authors recommended using multiple self-expanding and closed-loop stents [45].

\section{(2) Stenting therapy for AVM-drained venous sinus}

In addition to draining vein stenting in AVF, draining vein stenting in AVM has also been reported to improve poor venous drainage in AVM. Tsumoto et al. (2003) reported an AVM case in which the patient suffered clogged drainage due to sigmoid sinus stenosis and showed increased draining venous pressure; a sigmoid sinus stent angioplasty was conducted, and the patient recovered well. However, stent restenosis occurred after 3 months during follow-up and became more severe at six months, resulting in AVM rupture, bleeding and, thus, a poor prognosis, indicating that if stent restenosis occurs in the venous sinus, active treatment should be performed to avoid adverse consequences [46]. Higgins et al. (2013) reported a case of brainstem AVM with symptoms of headache and neurological deficits; because the AVM was inoperable and showed poor venous drainage, straight sinus stenting was first conducted, and the symptoms significantly improved. A slight headache appeared six months later, after which straight sinus stent dilatation and bilateral sinus stenting were performed, and the patient recovered well during the follow-up [47]. These results show that for certain AVMs, selective draining vein stenting can also produce satisfactory results. A summary of the clinical data is provided in Table 3.

Table 3. Reviewed literature on draining vein stenting in AVF and AVM

\begin{tabular}{|c|c|c|c|}
\hline Year & Author & Title & Research content \\
\hline 2005 & Liebig [41] & $\begin{array}{l}\text { Reconstructive treatment of dural arteriovenous fistulas of the } \\
\text { transverse and sigmoid sinus: transvenous angioplasty and } \\
\text { stent deployment }\end{array}$ & $\begin{array}{l}\text { A good effect from venous sinus stent implantation treatment was reported } \\
\text { in } 4 \text { cases of AVF, } 3 \text { of which also underwent simultaneous AVF emboliza- } \\
\text { tion. }\end{array}$ \\
\hline 2006 & Levrier [4] & $\begin{array}{l}\text { Use of a self-expanding stent with balloon angioplasty in the } \\
\text { treatment of dural arteriovenous fistulas involving the trans- } \\
\text { verse and/or sigmoid sinus: functional and neuroimag- } \\
\text { ing-based outcome in } 10 \text { patients }\end{array}$ & $\begin{array}{l}\text { A good, effective treatment was achieved for } 10 \text { cases of AVF, including } 8 \\
\text { cases of venous stenosis and } 2 \text { cases of thrombosis. Six underwent only } \\
\text { venous sinus balloon dilatation and stent angioplasty, while the other } 4 \text { cases } \\
\text { underwent stent-assisted coil embolization of AVF fistula after stent release. }\end{array}$ \\
\hline 2009 & Choi [42] & $\begin{array}{l}\text { Reconstructive treatment using a stent graft for a dural arteri- } \\
\text { ovenous fistula of the transverse sinus in the case of hypoplasia } \\
\text { of the contralateral venous sinuses: technical case report }\end{array}$ & $\begin{array}{l}\text { For dysplasia cases of venous sinus drainage of } \mathrm{AVF} \text {, it was reported that the } \\
\text { stent can also be released to reconstruct the hypogenetic venous sinus with a } \\
\text { good prognosis. }\end{array}$ \\
\hline 2009 & Hirata [43] & $\begin{array}{l}\text { Angioplasty and stent deployment in acute sinus thrombosis } \\
\text { following endovascular treatment of dural arteriovenous } \\
\text { fistulae }\end{array}$ & $\begin{array}{l}\text { The formation of acute thrombosis of the venous sinus in transvenous em- } \\
\text { bolization of AVF was reported, which showed good prognosis after stent } \\
\text { angioplasty. }\end{array}$ \\
\hline 2012 & Ohara [44] & $\begin{array}{l}\text { Superior sagittal sinus dural arteriovenous fistulas treated by } \\
\text { stent placement for an occluded sinus and transarterial embo- } \\
\text { lization. A case report }\end{array}$ & $\begin{array}{l}\text { A case of AVF involving the superior sagittal sinus was reported, which } \\
\text { underwent transarterial and transvenous AVF embolization after a sagittal } \\
\text { sinus balloon angioplasty as well as stenting and exhibited a good prognosis. }\end{array}$ \\
\hline 2015 & Takada [45] & $\begin{array}{l}\text { Torcular dural arteriovenous fistula treated via stent placement } \\
\text { and angioplasty in the affected straight and transverse sinuses: } \\
\text { case report }\end{array}$ & $\begin{array}{l}\text { For cases of AVF in the confluence sinus, it was reported that stents were } \\
\text { released in the straight sinus and transverse sinus after a balloon angioplasty. } \\
\text { Follow-up of patients showed good recovery, and the use of several } \\
\text { self-expanding and closed-loop stents was recommended. }\end{array}$ \\
\hline 2003 & Tsumoto & Restenosis of the sigmoid sinus after stenting for treatment of & A case of AVM with sigmoid sinus stenosis was reported, which showed a \\
\hline
\end{tabular}


[46] intracranial venous hypertension: case report

2013 Higgins [47]
Stenting venous outflow gives symptomatic improvement in a patient with an inoperable brainstem arteriovenous malformation rising pressure in the drainage vein and underwent the sigmoid sinus stenting surgery. Stenosis occurred during the third month of the follow-up period and became worse by the sixth month, indicating a bad prognosis with AVM rupture and hemorrhage.

A case of an inoperable brainstem AVM showing poor vein drainage was described, which underwent stent angioplasty in the straight sinus, and symptoms improved significantly. Stent dilation in the straight sinus and bilateral venous sinus stenting angioplasty were applied 6 months later, and the patient showed good recovery during follow-up.

\section{(3) Conclusion}

When direct treatment is difficult for certain AVFs or AVMs, evaluating the drainage vein is acceptable. VS-Stenting therapy may produce satisfactory effects if the drainage venous sinus is combined with stenosis.

\section{Stent application in tumor-mediated VSS}

Tumors in the vicinity of venous sinuses may invade the sinuses, producing VSS or an occlusion and, thus, corresponding clinical symptoms. However, current information on such conditions is limited, and the impact of brain tumors on the venous sinus are often ignored. In this study, the related literature has been analyzed and reviewed. Higgins et al. (2008) reported a case in which the patient exhibited a severe occipital cerebral edema after the tentorial and torcular meningiomas were surgically removed. The researchers thought this condition was due to a venous return disorder, and radiological examination showed a filling defect in the torcula region; hence, balloon dilatation and stenting were conducted, and the patient recovered well after surgery [5]. Certain meningiomas can directly invade the venous sinus and cause VSS and, therefore, often require stenting. Ganesan et al. (2008) reported a meningioma case that invaded the sagittal sinus, which produced VSS and high ICP; the patient underwent stent eluting with assisted radiation therapy, which yielded good results and provided new possibilities for treating VSS caused by a minor invasion of the sagittal sinus by meningiomas [48]. Zilani et al. (2009) reported a similar case with jugular foramen meningioma, which caused jugular bulb stenosis and impaired hearing and vision; balloon dilatation and stenting were conducted with postoperative adjuvant radiation therapy, which produced good therapeutic effects [49]. Similarly, Chausson et al. (2010) reported a case of multiple meningiomas in which one meningioma affected the torcula and transverse sinus, increasing the ICP; the patient underwent transverse sinus stenosis stenting and recovered well [50]. These results indicate that VS-Stenting can effectively alleviate symptoms, such as increased ICP for patients with tumor-caused VSS. A summary of the literature reviewed is provided in Table 4.

\section{Antiplatelet therapy in intracranial VS-Stenting}

Antiplatelet therapy is commonly necessary when VS-Stenting therapy is applied to the above diseases. Despite rare acute thrombosis in VS-Stenting, the recurrence rate of stenosis in long-term VS-Stenting without antiplatelet therapy is high [8]. The method for performing antiplatelet therapy remains controversial. In a study by Owler et al. in 2003, antiplatelet therapy was not provided preoperatively, but patients received aspirin and clopidogrel for 1 month and aspirin for half a year after a 2-day postoperative heparin anticoagulation treatment [15]. However, the study by Albuquerque et al. in 2011 recommended a 3-day preoperative application of aspirin and clopidogrel, a 3-month application of aspirin and clopidogrel and long-term aspirin use. Therefore, VS-Stenting patients were recommended to use aspirin and clopidogrel.

\section{Application prospects for intracranial VS-Stenting}

Intracranial venous sinus disease is an important part of vascular disease, particularly for patients who require venous sinus balloon angioplasty and stent angioplasty, and current information in this area is limited. However, the venous sinus system is an important component of hemodynamics and plays a special role. Poor venous sinus drainage is a major factor in the pathogenesis of many diseases, and it will become increasingly important in future treatments to actively recognize and treat venous sinus with poor drainage.

Therefore, upon reviewing the literature on $\mathrm{IIH}$, pulsatile tinnitus, sinus thrombosis formation, AVF, AVM and tumor-caused intracranial VSS, we found that for certain diseases, sinus balloon angioplasty and stenting may produce a satisfactory therapeutic effect. Although venous sinus stent restenosis and other complications can occur in certain cases, venous stent angioplasty has low risk, exhibits few complications and, thus, presents good prospects for application. 
Table 4. Reviewed scientific literature on applying stenting in tumor-induced venous sinus stenosis

\begin{tabular}{|c|c|c|c|}
\hline Year & Author & Title & Research content \\
\hline 2008 & Higgins [5] & $\begin{array}{l}\text { Severe brain edema caused by a meningio- } \\
\text { ma obstructing cerebral venous outflow and } \\
\text { treated with venous sinus stenting. Case } \\
\text { report }\end{array}$ & $\begin{array}{l}\text { A severe cerebral edema in the occipital lobe was reported, which occurred after a menin- } \\
\text { gioma and was attributed to a vein circumfluence obstacle. Imaging examination showed a } \\
\text { filling defect in the confluence sinus area. Balloon dilatation and stent angioplasty were } \\
\text { applied, and postoperative recovery was good. }\end{array}$ \\
\hline 2008 & Ganesan [48] & $\begin{array}{l}\text { Stent placement for management of a small } \\
\text { parasagittal meningioma. Technical note }\end{array}$ & $\begin{array}{l}\text { A meningioma that invaded the superior sagittal sinus and caused VSS was described, } \\
\text { leading to symptoms of high intracranial pressure. A good treatment effect was observed } \\
\text { upon release of the stent and by auxiliary radiotherapy. }\end{array}$ \\
\hline 2009 & Zilani [49] & $\begin{array}{l}\text { Venoplasty and stenting of a jugular fora- } \\
\text { men meningioma }\end{array}$ & $\begin{array}{l}\text { A case of a meningioma in the jugular foramen area was described, which caused a glomus } \\
\text { jugulare stenosis in the skull base. Balloon dilatation and stent angioplasty were applied and } \\
\text { produced a good therapeutic effect with auxiliary postoperative radiotherapy. }\end{array}$ \\
\hline 2010 & Chausson [50] & $\begin{array}{l}\text { Intracranial hypertension caused by a men- } \\
\text { ingioma compressing the transverse sinus }\end{array}$ & $\begin{array}{l}\text { A case of multiple meningiomas was reported, in which a meningioma involving the con- } \\
\text { fluence and transverse sinuses caused increased intracranial pressure, and the patient expe- } \\
\text { rienced a good recovery after stent angioplasty for transverse sinus stenosis. }\end{array}$ \\
\hline
\end{tabular}

\section{Competing Interests}

The authors have declared that no competing interest exists.

\section{References}

1. Thurtell MJ, Wall M. Idiopathic intracranial hypertension (pseudotumor cerebri): recognition, treatment, and ongoing management. Curr Treat Options Neurol. 2013; 15: 1-12.

2. Baomin L, Yongbing S, Xiangyu C. Angioplasty and stenting for intractable pulsatile tinnitus caused by dural venous sinus stenosis: a case series report. Otol Neurotol. 2014; 35: 366-70.

3. Borhani Haghighi A, Mahmoodi M, Edgell RC, Cruz-Flores S, Ghanaati H, Jamshidi M, et al. Mechanical thrombectomy for cerebral venous sinus thrombosis: a comprehensive literature review. Clin Appl Thromb Hemost. 2014; 20: 507-15.

4. Levrier O, Metellus P, Fuentes S, Manera L, Dufour H, Donnet A, et al. Use of a self-expanding stent with balloon angioplasty in the treatment of dural arteriovenous fistulas involving the transverse and/or sigmoid sinus: functional and neuroimaging-based outcome in 10 patients. J Neurosurg. 2006; 104: 254-63.

5. Higgins JN, Burnet NG, Schwindack CF, Waters A. Severe brain edema caused by a meningioma obstructing cerebral venous outflow and treated with venous sinus stenting. Case report. J Neurosurg. 2008; 108: 372-6.

6. Ahmed RM, Wilkinson M, Parker GD, Thurtell MJ, Macdonald J, McCluskey PJ, et al. Transverse sinus stenting for idiopathic intracranial hypertension: a review of 52 patients and of model predictions. AJNR Am J Neuroradiol. 2011; 32: 1408-14.

7. Albuquerque FC, Dashti SR, Hu YC, Newman CB, Teleb M, McDougall CG, et al. Intracranial venous sinus stenting for benign intracranial hypertension: clinical indications, technique, and preliminary results. World Neurosurg. 2011; 75: 648-52; discussion 592-5.

8. Starke RM, Wang T, Ding D, Durst CR, Crowley RW, Chalouhi N, et al Endovascular Treatment of Venous Sinus Stenosis in Idiopathic Intracranial Hypertension: Complications, Neurological Outcomes, and Radiographic Results. ScientificWorldJournal. 2015; 2015: 140408.

9. Puffer RC, Mustafa W, Lanzino G. Venous sinus stenting for idiopathic intracranial hypertension: a review of the literature. J Neurointerv Surg. 2013; 5: 483-6.

10. Teleb MS, Cziep ME, Lazzaro MA, Gheith A, Asif K, Remler B, et al. Idiopathic Intracranial Hypertension. A Systematic Analysis of Transverse Sinus Stenting. Interv Neurol. 2013; 2: 132-43.

11. Bussiere $M$, Falero $R$, Nicolle $D$, Proulx A, Patel V, Pelz D. Unilateral transverse sinus stenting of patients with idiopathic intracranial hypertension. AJNR Am J Neuroradiol. 2010; 31: 645-50.

12. Fields JD, Javedani PP, Falardeau J, Nesbit GM, Dogan A, Helseth EK, et al. Dural venous sinus angioplasty and stenting for the treatment of idiopathic intracranial hypertension. J Neurointerv Surg. 2013; 5: 62-8.

13. Ducruet AF, Crowley RW, McDougall CG, Albuquerque FC. Long-term patency of venous sinus stents for idiopathic intracranial hypertension. J Neurointerv Surg. 2014; 6: 238-42.

14. Higgins JN, Cousins C, Owler BK, Sarkies N, Pickard JD. Idiopathic intracranial hypertension: 12 cases treated by venous sinus stenting. J Neurol Neurosurg Psychiatry. 2003; 74: 1662-6.

15. Owler BK, Parker G, Halmagyi GM, Dunne VG, Grinnell V, McDowell D, et al. Pseudotumor cerebri syndrome: venous sinus obstruction and its treatment with stent placement. J Neurosurg. 2003; 98: 1045-55.

16. Kumpe DA, Bennett JL, Seinfeld J, Pelak VS, Chawla A, Tierney M. Dural sinus stent placement for idiopathic intracranial hypertension. J Neurosurg. 2012; 116: 538-48.
17. Teleb MS, Rekate H, Chung S, Albuquerque FC. Pseudotumor cerebri presenting with ataxia and hyper-reflexia in a non-obese woman treated with sinus stenting. J Neurointerv Surg. 2012; 4: e22.

18. Elder BD, Rory Goodwin C, Kosztowski TA, Radvany MG, Gailloud P, Moghekar A, et al. Venous sinus stenting is a valuable treatment for fulminant idiopathic intracranial hypertension. J Clin Neurosci. 2015; 22: 685-9.

19. Fargen KM, Velat GJ, Lewis SB, Hoh BL, Mocco J, Lawson MF. Concomitant intracranial pressure monitoring during venous sinus stenting for intracranial hypertension secondary to venous sinus stenosis. J Neurointerv Surg. 2013; 5 : e22.

20. Ding D, Starke RM, Durst CR, Crowley RW, Liu KC. Venous stenting with concurrent intracranial pressure monitoring for the treatment of pseudotumor cerebri. Neurosurg Focus. 2014; 37: 1.

21. Esfahani DR, Stevenson M, Moss HE, Amin-Hanjani S, Aletich V, Jain S, et al. Quantitative Magnetic Resonance Venography is Correlated With Intravenous Pressures Before and After Venous Sinus Stenting: Implications for Treatment and Monitoring. Neurosurgery. 2015.

22. Paquet C, Poupardin M, Boissonnot M, Neau JP, Drouineau J. Efficacy of unilateral stenting in idiopathic intracranial hypertension with bilateral venous sinus stenosis: a case report. Eur Neurol. 2008; 60: 47-8.

23. Lazzaro MA, Darkhabani Z, Remler BF, Hong SH, Wolfe TJ, Zaidat OO, et al. Venous sinus pulsatility and the potential role of dural incompetence in idiopathic intracranial hypertension. Neurosurgery. 2012; 71: 877-83.

24. Goodwin CR, Elder BD, Ward A, Orkoulas-Razis D, Kosztowski TA, Hoffberger J, et al. Risk factors for failed transverse sinus stenting in pseudotumor cerebri patients. Clin Neurol Neurosurg. 2014; 127: 75-8.

25. Biousse V, Bruce BB, Newman NJ. Update on the pathophysiology and management of idiopathic intracranial hypertension. J Neurol Neurosurg Psychiatry. 2012; 83: 488-94.

26. Dessardo NS, Dessardo S, Sasso A, Sarunic AV, Dezulovic MS. Pediatric idiopathic intracranial hypertension: clinical and demographic features. Coll Antropol. 2010; 34 Suppl 2: 217-21.

27. Friedman DI. Cerebral venous pressure, intra-abdominal pressure, and dural venous sinus stenting in idiopathic intracranial hypertension. J Neuroophthalmol. 2006; 26: 61-4.

28. Kelly LP, Saindane AM, Bruce BB, Ridha MA, Riggeal BD, Newman NI, et al. Does bilateral transverse cerebral venous sinus stenosis exist in patients without increased intracranial pressure? Clin Neurol Neurosurg. 2013; 115: 1215-9.

29. Levitt MR, Albuquerque FC, Ducruet AF, Kalani MY, Mulholland CB, McDougall CG. Venous sinus stenting for idiopathic intracranial hypertension is not associated with cortical venous occlusion. J Neurointerv Surg. 2015.

30. Ahmed RM, Zmudzki F, Parker GD, Owler BK, Halmagyi GM. Transverse sinus stenting for pseudotumor cerebri: a cost comparison with CSF shunting. AJNR Am J Neuroradiol. 2014; 35: 952-8.

31. Russell EJ, De Michaelis BJ, Wiet R, Meyer J. Objective Pulse-Synchronous "Essential" Tinnitus due to Narrowing of the Transverse Dural Venous Sinus. Int Tinnitus J. 1995; 1: 127-37.

32. Donnet A, Metellus P, Levrier O, Mekkaoui C, Fuentes S, Dufour H, et al. Endovascular treatment of idiopathic intracranial hypertension: clinical and radiologic outcome of 10 consecutive patients. Neurology. 2008; 70: 641-7.

33. Schoeff S, Nicholas B, Mukherjee S, Kesser BW. Imaging prevalence of sigmoid sinus dehiscence among patients with and without pulsatile tinnitus. Otolaryngol Head Neck Surg. 2014; 150: 841-6.

34. Lenck S, Mosimann PJ, Labeyrie MA, Houdart E. Pulsatile tinnitus caused by an aneurysm of the transverse-sigmoid sinus: a new case report and review of literature. J Neuroradiol. 2012; 39: 276-9.

35. Grewal AK, Kim HY, Comstock RH, 3rd, Berkowitz F, Kim HJ, Jay AK. Clinical presentation and imaging findings in patients with pulsatile tinnitus and sigmoid sinus diverticulum/dehiscence. Otol Neurotol. 2014; 35: 16-21.

36. Signorelli F, Mahla K, Turjman F. Endovascular treatment of two concomitant causes of pulsatile tinnitus: sigmoid sinus stenosis and ipsilateral jugular bulb diverticulum. Case report and literature review. Acta Neurochir (Wien). 2012; 154: 89-92. 
37. Raychev R, Tateshima S, Rastogi S, Balgude A, Yafeh B, Saver JL, et al. Successful treatment of extensive cerebral venous sinus thrombosis using a combined approach with Penumbra aspiration system and Solitaire FR retrieval device. J Neurointerv Surg. 2014; 6: e32.

38. Prasad RS, Michaels LA, Roychowdhury S, Craig V, Sorrell A, Schonfeld S. Combined venous sinus angioplasty and low-dose thrombolytic therapy for treatment of hemorrhagic transverse sinus thrombosis in a pediatric patient. J Pediatr Hematol Oncol. 2006; 28: 196-9.

39. Formaglio M, Catenoix H, Tahon F, Mauguiere F, Vighetto A, Turjman F. Stenting of a cerebral venous thrombosis. J Neuroradiol. 2010; 37: 182-4.

40. Vanlandingham M, Fox B, Hoit D, Elijovich L, Arthur AS. Endovascular treatment of intracranial dural arteriovenous fistulas. Neurosurgery. 2014; 74 Suppl 1: S42-9.

41. Liebig T, Henkes H, Brew S, Miloslavski E, Kirsch M, Kuhne D. Reconstructive treatment of dural arteriovenous fistulas of the transverse and sigmoid sinus: transvenous angioplasty and stent deployment. Neuroradiology. 2005; 47: 543-51.

42. Choi BJ, Lee TH, Kim CW, Choi CH. Reconstructive treatment using a stent graft for a dural arteriovenous fistula of the transverse sinus in the case of hypoplasia of the contralateral venous sinuses: technical case report. Neurosurgery. 2009; 65: E994-6; discussion E6.

43. Hirata E, Higashi T, Iwamuro Y, Watanabe Y, Ando M, Arakawa Y, et al. Angioplasty and stent deployment in acute sinus thrombosis following endovascular treatment of dural arteriovenous fistulae. J Clin Neurosci. 2009; 16: 725-7.

44. Ohara N, Toyota S, Kobayashi M, Wakayama A. Superior sagittal sinus dural arteriovenous fistulas treated by stent placement for an occluded sinus and transarterial embolization. A case report. Interv Neuroradiol. 2012; 18: 333-40.

45. Takada S, Isaka F, Nakakuki T, Mitsuno Y, Kaneko T. Torcular dural arteriovenous fistula treated via stent placement and angioplasty in the affected straight and transverse sinuses: case report. J Neurosurg. 2015: 1-6.

46. Tsumoto T, Miyamoto T, Shimizu M, Inui Y, Nakakita K, Hayashi S, et al. Restenosis of the sigmoid sinus after stenting for treatment of intracranial venous hypertension: case report. Neuroradiology. 2003; 45: 911-5.

47. Higgins JN, Kirkpatrick PJ. Stenting venous outflow gives symptomatic improvement in a patient with an inoperable brainstem arteriovenous malformation. Br J Neurosurg. 2013; 27: 698-700.

48. Ganesan D, Higgins JN, Harrower T, Burnet NG, Sarkies NJ, Manford M, et al. Stent placement for management of a small parasagittal meningioma. Technical note. J Neurosurg. 2008; 108: 377-81.

49. Zilani G, Pereira EA, Baig F, Uberoi R, Kuker W, Kerr RS. Venoplasty and stenting of a jugular foramen meningioma. Br J Neurosurg. 2009; 23: 557-60.

50. Chausson N, Bocquet J, Aveillan M, Olindo S, Signate A, Merle H, et al. Intracranial hypertension caused by a meningioma compressing the transverse sinus. J Clin Neurosci. 2010; 17: 1589-92. 